\section{Prevention of neonatal ophthalmia}

The concern expressed by Dr. J. Jacobs in his letter "Prevention of neonatal ophthalmia" (Can Med Assoc $J$ 1984; 130: 970) that administration of silver nitrate may lead to chemical conjunctivitis, which may affect mother-infant bonding, is reasonable. In addition, the use of silver nitrate is neither $100 \%$ effective in preventing gonococcal ophthalmia ${ }^{1,2}$ nor effective in preventing chlamydial ophthalmia. ${ }^{3}$

However, I disagree with Dr. Jacobs' suggestion to delay treatment. Gonococcal ophthalmia is highly contagious. Furthermore, as the incubation period of chlamydial conjunctivitis is approximately 5 to 13 days a significant number of cases of chlamydial ophthalmia may be missed if prophylactic treatment is not administered at birth.

The use of erythromycin ophthalmic ointment has been shown to be effective in the prophylaxis of both gonococcal and chlamydial conjunctivitis. ${ }^{4}$ I have attended at least 200 newborn infants in the last 6 months; all received erythromycin ophthalmic ointment for prophylaxis at birth, and in none did chemical conjunctivitis develop. I therefore recommend the routine use of erythromycin ophthalmic ointment for prophylaxis of neonatal ophthalmia.

Alexander LeUnG, MB, BS, FrCP[C], MrCP, MRCP[I]

Pediatric consultant Alberta Children's Hospital Calgary, Alta.

\section{References}

1. Doraiswamy B, Hammerschlag MR, Pringle GF et al: Ophthalmia neonatorum caused by beta-lactamase-producing
Neisseria gonorrhoeae. JAMA 1983; 250: 790-791

2. Rothenberg R: Ophthalmia neonatorum due to Neisseria gonorrhoeae. Sex Transm Dis 1979; 65: 187-191

3. Bernstein GA, Davis JP, Katcher ML: Prophylaxis of neonatal conjunctivitis: an analytic review. Clin Pediatr (Phila) 1982; 21: $545-550$

4. Hammerschlag MR, Chandler JW, AleXANDER ER et al: Erythromycin ointment for ocular prophylaxis of neonatal chlamydial infection. JAMA 1980; 244: 2291-2293

\section{Meningitis caused by Bacteroides fragilis}

Of central nervous system infections, brain abscess is the one most frequently associated with anaerobic bacteria. However, the real incidence of meningeal infection in the absence of accompanying brain abscess has not been established.

We describe a patient with chronic otitis media in whom meningitis due to Bacteroides fragilis developed.

\section{Case report}

A 36-year-old man with a history of recurrent episodes of otitis media on the right side was admitted to hospital because of headache, fever, chills and pain in the right ear persisting for 5 days. Clinical signs

CMAJ tries to publish as wide a selection of letters to the editor as possible. We can accept more letters and publish them more promptly if they are short and convenient to edit. We ask that letters be no longer than two typescript pages (450 words) and be typed double-spaced with wide margins, like a manuscript. of suppurative otitis (yellow drainage, pain and fever) had developed 2 days before admission.

The patient was alert and in no acute distress but had stiffness in his neck. His temperature was $38^{\circ} \mathrm{C}$ and his blood pressure $120 / 90 \mathrm{~mm}$ $\mathrm{Hg}$. The leukocyte count was $16.5 \times$ $10^{\circ} / \mathrm{L}$, with $85 \%$ polymorphonuclear leukocytes and 3\% band cells. An electrocardiogram and a chest $x$-ray film were normal. The cerebrospinal fluid was clear but had a leukocyte count of $95 \times 10^{6} / \mathrm{L}$ (80\% polymorphonuclear leukocytes and $20 \%$ lymphocytes), a protein level of 0.90 $\mathrm{g} / \mathrm{L}$ and a glucose level of 3.6 $\mathrm{mmol} / \mathrm{L}$ (the blood glucose level was $6.1 \mathrm{mmol} / \mathrm{L}$ ); the results of Gram and Ziehl-Neelsen staining of the fluid were negative. Aerobic and anaerobic organisms were cultured from three blood specimens, and intravenous administration of chloramphenicol, $1 \mathrm{~g} / 6 \mathrm{~h}$, and ampicillin, $2 \mathrm{~g} / 4 \mathrm{~h}$, was begun.

Twelve hours after admission the patient became confused and suffered respiratory arrest. Efforts at cardiopulmonary resuscitation were unsuccessful, and the patient died. Three days after admission cultures of blood and of the cerebrospinal fluid yielded $B$. fragilis. No aerobic organisms were isolated. The microorganism was reported to be sensitive to chloramphenicol, clindamycin, metronidazole and cefoxitin sodium.

A postmortem examination of the brain showed recent severe acute purulent bacterial meningitis, with moderate perivascular and pericellular edema in the surrounding parenchyma, vascular congestion and inflammatory polymorphonuclear infiltrates, as well as acute interstitial neuritis in the petrous portion of the temporal bone and in the canal of the eighth cranial nerve. 